\title{
O papel dos BRICS nas relações diplomáticas entre Brasil e China
}

\author{
Elisiane Dondé Dal Molin ${ }^{1}$ \\ Yasmin Lenz Piccoli Castelli ${ }^{2}$ \\ Emanuelle De Nadal $^{3}$
}

\begin{abstract}
Resumo: Em 1974 China e Brasil iniciaram a construção de um diálogo que consolidou, desde então, importante parceria para os dois países, sobretudo nas áreas de comércio, infraestrutura, finanças, tecnologia, energia e alimentação. Tal conexão se tornou mais próxima após a inclusão do Brasil como membro dos BRICS, entidade formada por Brasil, Rússia, Índia, China e África do Sul. Mas, seria possível afirmar que as relações se intensificaram a partir desta inclusão? Diante da questão, o objetivo do trabalho apresentado é identificar de que maneira a criação dos BRICS influenciou no relacionamento entre China e Brasil, por meio da realização de uma pesquisa teórica e exploratória. Dadas as constatações geradas, entende-se que essas trocas diplomáticas entre os dois Estados se intensificaram devido a interação no bloco dos BRICS, contudo, alguns sinais de alerta são percebidos, dada a possível dependência do Brasil aos rumos políticos e econômicos chineses.
\end{abstract}

Palavras-chave: Brasil. China. Relações diplomáticas. BRICS.

\section{BRICS' role in the diplomatic relations between Brazil and China}

1 Professora da Universidade do Vale do Itajaí (Santa Catarina) curso de Relações Internacionais. E-mail: elisianed@univali.br

${ }^{2}$ Graduanda do $7^{\circ}$ período de Relações Internacionais da Universidade do Vale do Itajaí. E-mail: yasminlenzp@gmail.com

${ }^{3}$ Graduanda do $7^{\circ}$ período de Relações Internacionais da Universidade do Vale do Itajaí. E-mail: manuh_denadal@hotmail.com 
$|2|$

O papel dos Brics nas relações diplomáticas...

\begin{abstract}
In 1974 China and Brazil began the building of a dialogue that consolidated, ever since, an important partnership for both countries, especially in areas of trade, infrastructure, finance, technology, energy and food. Such connection became closer after Brazil's inclusion as a member of BRICS, an entity formed by Brazil, Russia, India, China and South Africa. However, could it be said that relations were intensified from this inclusion? Giving the question, the purpose of this paper is to identify how the creation of the BRICS influenced in the relationship between China and Brazil, using a theoretical and exploratory research. Given the findings, it is understood that these diplomatic exchanges between the two states have been intensified due to interaction in the BRICS bloc, however, some warning signs are perceived about a Brazil's dependency on Chinese political and economic directions.
\end{abstract}

Keywords: Brazil. China. Diplomatic relations. BRICS.

\title{
El papel de los BRICS en las relaciones diplomáticas entre Brasil y China
}

Resumen: En 1974 China y Brasil iniciaron la construcción de un diálogo que consolidó desde entonces en importante asociación para los dos países, sobre todo en las áreas de comercio, infraestructura, finanzas, tecnología, energía y alimentación. Esta relación se volvió más cercana después de la inclusión de Brasil como miembro de los BRICS, entidad formada por Brasil, Rusia, India, China y Sudáfrica. Pero, ¿es posible afirmar que tales relaciones se intensificaron a partir de esto? Ante a la pregunta, el objetivo del trabajo presentado es identificar cómo la creación de los BRICS influenció en la relación entre China y Brasil, por medio de una investigación teórica y exploratoria. Por cuenta de las constataciones generadas, se entiende que estos cambios diplomáticos de los dos Estados se intensificaron por la interacción en el bloque de BRICS, pero, alguns sinales de alerta son percebidos por la posibilidad de dependencia de Brasil a los rumbos políticos y económicos chinos.

Palabras llave: Brasil. China. Relaciones diplomáticas. BRICS.

\section{Introdução}

O BRICS, grupo formado por Brasil, Rússia, Índia, China e África do Sul, consiste em uma entidade político-diplomática que, desde o início, carregava consigo a previsão de reunir economias em franco crescimento, somadas a grandes faixas territoriais. Neste alinhamento demonstrado por tais países, um relacionamento se destaca: as ligações entre China e Brasil, iniciadas ainda em 1974 e que, desde então, frutificaram em inúmeros acordos e reuniões 
bilaterais, demonstrações estas de interesses econômicos e políticos mútuos, rumo à cooperação.

Todavia, a partir da conexão existente entre China e Brasil, seria possível afirmar que suas relações diplomáticas foram intensificadas devido à interação destes Estados no bloco dos BRICS? Dada a problemática apresentada, o objetivo do presente trabalho é identificar de que forma a criação dos BRICS influenciou a conexão entre Brasil e China, por meio do histórico das relações diplomáticas destes países no período 1974-2009; da identificação de tais relações na perspectiva dos BRICS (desde a entrada do Brasil até o ano de 2014, na reunião da $6^{\circ}$ Cúpula, que institucionalizou a entidade); e do exame dos acordos estratégicos firmados entre Brasil e China pós-2008.

Esta pesquisa é de caráter teórico-empírico e monográfico, decorrente da observância dos fatores que influenciam o tema proposto, analisados em diferentes aspectos, tendo como referenciais informações históricas, dados atuais (primários e secundários) representativos da produção acadêmica sobre o tema e documentos oficiais, publicados pelo governo brasileiro.

Para o alcance do objetivo exposto, o artigo compõe-se de três seções: a primeira contém um resgate histórico das tratativas iniciais firmadas entre os dois países em 1974 até 2008, quando o Brasil passou a integrar o BRICS; na sequência, demonstrar-se-ão as relações bilaterais sino-brasileiras nas reuniões do grupo, com o intuito de compreender os resultados da integração entre os dois países perante as agendas do bloco e; finalmente, a identificação dos alvitres dessa aproximação, cultivada até os dias atuais.

\section{1 - As relações diplomáticas Brasil-China (1974-2008)}

No ano de 1974, as relações diplomáticas entre o Brasil e a República Popular da China foram estabelecidas pelo reconhecimento do Partido Comunista Chinês (PCCh) como governo legítimo da China. O episódio ocorreu em um contexto particular à política brasileira: o início do mandato presidencial do militar Ernesto Geisel e de seu projeto de "liberalização cuidadosamente controlada", no desígnio de retornar o Brasil ao 
$|4|$

O papel dos Brics nas relações diplomáticas...

Estado democrático com controle político. O cenário da política internacional era de instabilidade, causada pelo atrito entre Estados Unidos e União Soviética e pelo deslocamento do centro gravitacional do sistema internacional: de Leste-Oeste para NorteSul, encetado na Conferência de Bandung e completado com a descolonização africana e a formação do Grupo dos 77, composto por países não alinhados aos interesses das superpotências (GONÇALVES; MIYAMOTO, 1993).

Devido aos novos direcionamentos da cena internacional, a política externa brasileira adotou uma linha de abertura chamada "pragmatismo responsável" (RICUPERO, 2017). Enquanto isso, a reaproximação de Estados Unidos e China na década de 1970, mostrou a importância chinesa como polo de poder mundial. Para o Brasil, reconhecer a República Popular da China e construir laços diplomáticos seria a abertura ao novo contexto internacional, rompendo as barreiras ideológicas da Guerra Fria na busca de alianças estratégicas (RICUPERO, 2017).

Assim como o Brasil, a China passava por transformações. Em 1976 Mao Tsé-tung, líder chinês que protagonizou a Revolução Chinesa de 1949 e proclamou a República Popular da China (HOBSBAWM, 1994), veio a falecer. As condutas de Mao Tsé-tung deixaram marcas: ao mesmo tempo em que é uma personalidade cultuada na China por seus feitos de libertação do "período de humilhações", em seu governo a população chinesa sofreu com ações políticas autoritárias, representadas pela Revolução Cultural, o radicalismo do Estado e pela campanha de ódio aos valores do passado, levando o governo chinês a uma grande crise (BARBIERI JUNIOR, 2015).

Em 1978 Deng Xiaoping, antigo companheiro de lutas de Mao, foi nomeado Secretário Geral e líder do Partido Comunista Chinês, incumbido da missão de conciliar divergências entre pró-socialismo e pró-capitalismo, pertencentes a uma sociedade empobrecida, sufocada pelo dogmatismo (BARBIERI JUNIOR, 2015). A partir do Programa "Quatro Modernizações" (desenvolvimento da agricultura, indústria, ciência e tecnologia); da inserção da China internacionalmente como Estado-membro 
do Conselho de Segurança da Organização das Nações Unidas (ONU); e da entrada de capital estrangeiro por intermédio dos ultramarinos chineses, a China começou a trilhar o caminho de recuperação da grandeza perdida.

Nos anos de 1980, Brasil e China alinharam suas políticas externas em busca do protagonismo regional e do aumento da independência no cenário internacional, tendo a modernização como prioridade, tanto que, entre 1984 e 1985, metade das trocas comerciais chinesas ocorreram com a América Latina. Essa postura foi importante à condução de uma política externa de caráter universal, condizente com as pretensões chinesas, somadas a visitas diplomáticas mútuas de líderes chineses e brasileiros, motivadoras inclusive de um acordo de cooperação nuclear (BECARD, 2008).

A década de 1990 inaugurou uma nova discussão nas relações sino-brasileiras. Em 1993, durante "[...] visita ao Brasil do vice-primeiro-ministro Zhu Rongji seria cunhada a expressão 'Parceria Estratégica' às relações bilaterais", como demonstração da importância do diálogo sino-brasileiro à evolução das políticas internas e externas dos países (HOLANDA, 2016, p. 51).

A evolução das conversas para este patamar era primordial à política externa chinesa, considerando que o governo brasileiro de Itamar Franco "[...] procurou desdramatizar as relações com os Estados Unidos evitando tanto alianças incondicionais quanto enfrentamentos" (SARAIVA, 2007, p. 46). Portanto, o governo chinês, ao caracterizar a relação bilateral sino-brasileira como estratégica, direcionava a política externa brasileira ao diálogo com os países em desenvolvimento (BECARD, 2008).

Concomitante ao contexto traçado, o fim da Guerra Fria exigiu dos Estados visões de políticas externas adaptadas à nova ordem mundial. O governo de Itamar Franco focou nesse ponto (LIMA, 2007) e a diplomacia inaugurada possibilitou a cooperação Sul-Sul e o modelo system-affecting, originário da definição de Keohane "system-affecting state", no qual Estados como África do Sul, Índia, China e Rússia, detentores de recursos e de atuação ativa, fossem capazes de afetar o andamento de certos temas da política internacional (SARAIVA, 2007). 
$|6|$

O papel dos Brics nas relações diplomáticas...

A definição de parceria estratégica, a partir disso, caracterizou o relacionamento sino-brasileiro por três vertentes de cooperação: econômica/ social, política e científica/ tecnológica (FUJITA, 2003 apud DICK, 2006). No entanto, dados os acordos existentes, nota-se ênfase somente na cooperação científica/ tecnológica, com o desenvolvimento de satélites de sensoriamento remoto (OLIVEIRA, 2004).

Cunhada a parceria estratégica sino-brasileira, as relações entre os Estados se aprofundaram no governo de Fernando Henrique Cardoso (FHC), pelo avanço das políticas de cooperação com o presidente chinês Jiang Zemin. FHC, em seus dois mandatos (1995-1998 e 1999-2002), sinalizou uma política externa orientada à “autonomia pela participação e integração" (RICUPERO, 2017). O contexto global pós-Guerra Fria trouxe uma particularidade à essa política externa brasileira, caracterizada até então com a lógica da autonomia pela distância: a agenda internacional do Brasil foi reformulada na busca da autonomia pela integração e participação internacional (RICUPERO, 2017).

Devido às mudanças estruturais, a política externa brasileira de FHC foi marcada por diretrizes que visavam "[...] o pacifismo, a defesa dos princípios de autodeterminação e não intervenção e o pragmatismo como instrumento necessário e eficaz à defesa dos interesses do país" (VIGEVANI; OLIVEIRA; CINTRA, 2003, p. 31). Tal política pretendia reintroduzir o Brasil no modelo neoliberal incorporado pelos processos de globalização, trabalhando os conceitos de universalismo, a busca pelo multilateralismo no perfil de global trader e a diplomacia presidencial. $\mathrm{O}$ multilateralismo presente nas estratégias de política externa possibilitou relações com países de crescente desenvolvimento, como China, Índia e Rússia (um esboço do que seria o BRICS anos à frente), pela cooperação nuclear, aeroespacial e a estruturação de um sistema multipolar, em contraponto à unilateralidade estadunidense (VIZENTINI, 2005).

Em continuidade à parceria, Fernando Henrique Cardoso fez sua primeira visita oficial à China em 1995, oportunidade na qual ressaltou a importância das relações bilaterais sino- 
brasileiras e os interesses econômicos do Brasil em integrar as empresas brasileiras aos projetos chineses de modernização de infraestruturas (formação das Gigantes nacionais chinesas); aumentar a troca comercial (sobretudo nos setores agrícolas) e; melhorar a balança comercial entre os países. A visita resultou no avanço do Programa Satélite Sino-Brasileiro de Recursos Terrestres (CBERS), pela assinatura do "Acordo sobre Segurança Técnica de Desenvolvimento do CBERS" e da "Ata de Entendimento sobre o Fortalecimento e a Expansão da Cooperação Tecnológica Espacial Brasil-China" (BIATO, 2010).

Tal cooperação entre os dois países obteve relativo avanço na administração de FHC, com prospecções a uma cooperação política dentro das instituições internacionais, levando em consideração as dimensões econômicas e políticas da China na posição de único Estado em desenvolvimento a ocupar um assento permanente no Conselho de Segurança da ONU (VALENTE; ALBUQUERQUE, 2015).

Apesar dos esforços da administração $\mathrm{FHC}$, os últimos anos de 1990 apresentaram diminuição nos fluxos comerciais sinobrasileiras, atingindo em 1999 o ponto mais baixo desde 1994. O recuo chinês foi uma consequência da crise financeira asiática de 1997, que causou desvalorização cambial. No caso do Brasil, o país foi assolado por uma crise financeira em 1998, agravada pela depreciação da moeda brasileira e a redução da demanda nacional por produtos chineses (BIATO, 2010).

Na década de 2000 a China reforçou novamente os laços bilaterais com o Brasil consolidados pelo BRICS e estendidos para outras áreas de cooperação. Os números exemplificam esse fato: na economia, "[...] de 2000 a 2004, houve aumento, em 351,8\%, das compras chinesas no Brasil, e em 106\%, das compras brasileiras na China, o que levou este país a transformar-se no quarto principal parceiro comercial do Brasil" (BECARD, 2011, p. 36). A correlação também foi fortalecida globalmente, por meio de votações uniformes nos fóruns internacionais. Em 2003, por exemplo, junto à Índia, os dois países foram contrários ao protecionismo de Estados Unidos, Canadá e União Europeia (VÉRAS, 2015). 
|81

O papel dos Brics nas relações diplomáticas...

$\mathrm{O}$ vínculo construído nos anos anteriores atingiu a maturidade a partir do governo Lula (2003-2010), dado o fortalecimento do regionalismo na cooperação Sul-Sul e da meta de ascensão do Brasil como liderança regional. Em paralelo, o governo investiu na cooperação Sul-Sul system-affecting, pela abertura do Fórum de Diálogo IBAS entre Índia, Brasil e África do Sul, para fortalecer a inserção internacional dos membros em diálogos multilaterais (SARAIVA, 2007). A China, por sua vez, ganhou destaque pela posição proativa exercida no cenário internacional.

Tais elementos foram cruciais e estreitaram as conexões sino-brasileiras, tanto que o então presidente brasileiro Luiz Inácio "Lula" da Silva visitou oficialmente a China em 2004 e 2009, e o Presidente $\mathrm{Hu}$ Jintao veio ao Brasil em 2004 e 2010. A primeira ida de Lula foi acompanhada por nove ministros, seis governadores e 400 empresários - uma das mais relevantes da gestão (BECARD, 2011). Nessa incursão, Lula destacou que os dois países procuravam integrar-se às correntes internacionais de comércio e investimento, respeitando a autonomia dos processos decisórios, na modificação das regras (consideradas por ele injustas) que conduzem o comércio internacional (SILVA, 2004, p. 1 apud DICK, 2006). Ressalta-se a criação da Comissão Sino-Brasileira de Alto Nível de Concertação e Cooperação (COSBAN), para a promoção de políticas de desenvolvimento nos planos econômico, comercial, financeiro, científico, técnico, acadêmico e cultural (VÉRAS, 2015).

Durante a segunda visita oficial de Lula à China em 2009 (no aniversário de 35 anos das relações sino-brasileiras), as conquistas bilaterais efetivadas até então foram elencadas em um comunicado conjunto. O documento listou a criação da Agenda China na área comercial, a COSBAN, o Diálogo Estratégico (2007) e o Diálogo Financeiro Brasil-China (2008) (BECARD, 2011). Além destes, emergiu o BRICS, bloco em que ambos passaram a cooperar a partir do ano de 2008 (SENADO FEDERAL, 2018). Tal adesão reafirmou a convergência de interesses existente entre Brasil e China, que logrou importantes resultados, descrito na próxima seção. 


\section{2 - O papel dos BRICS nas relações diplomáticas e na cooperação Brasil-China}

A sigla BRICs ${ }^{4}$ foi criada por Jim $\mathrm{O}^{\prime} \mathrm{Neill}$, chefe de pesquisas econômicas da Goldman Sachs, ao ser citada no relatório Building Better Global Economic BRICs, publicado em 2001. Os aspectos geradores da categoria BRICs foram econômicos, ao abranger países em rápido desenvolvimento e com altos indicadores, tais como Produto Interno Bruto (PIB) e renda per capita. Desta forma, a sigla incluía Brasil, Rússia, Índia e China, países classificados pelo estudo com maior propensão a desenvolverem-se na economia mundial (STUENKEL, 2017).

Concomitante às proposições de $\mathrm{O}^{\prime}$ Neill, os países do BRICS (incluindo a África do Sul) são parte do system-affecting. Estados com este caráter tendem a interagir em fóruns multilaterais e nas iniciativas bilaterais com outros países em desenvolvimento, como as relações bilaterais sino-brasileiras citadas na abordagem anterior. A cooperação entre Índia, Brasil e África do Sul existe desde o início da década de 2000, a partir do Fórum de Diálogo do IBAS (SARAIVA, 2007).

Em paralelo, houve a formação do RIC, bloco de cooperação da Ásia, entre Rússia, Índia e China. Em maio de 2008, ocorreu a “[..] primeira reunião formal entre os ministros das Relações Exteriores do grupo dos BRICs" (STUENKEL, p.31, 2017). A partir do ano de 2009, os líderes das potências do RIC passaram a se encontrar anualmente com o Brasil, formando o BRIC de maneira efetiva. No ano de 2011, a África do Sul foi inclusa ao grupo, concretizando a formação dos BRICS, bloco de cooperação Sul-Sul como iniciativa à reorganização do sistema internacional e uma alternativa à ordem de poder Norte-Sul (BRASIL, 2019).

\footnotetext{
${ }^{4}$ O termo BRICs, com a letra "S" em minúsculo, sinaliza o bloco formado por Brasil, Rússia, Índia e China, válido até o ano de 2010. Em 2011, transformouse em BRICS, com S maiúsculo, pela inclusão da África do Sul (BRASIL, 2019, não paginado).
} 
$|10|$

O papel dos Brics nas relações diplomáticas...

Stuenkel (2017, p. 21) destaca a importância da criação dos BRICs para uma nova configuração da ordem global, símbolo da narrativa que nos anos 1990 parecia distante, mas na década de 2000 ganhava sentido: transferência de poder dos Estados Unidos e da Europa, para potências emergentes como China, Índia e Brasil, "[...] deixando o mundo menos ocidentalizado e mais ideologicamente diversificado. A sigla BRICs ao mesmo tempo capturava e ampliava essa mudança de distribuição de poder na ordem global".

Portanto, a partir de 2009, o BRIC toma corpo como um bloco, quando "[...] os Chefes de Estado e de governo do agrupamento passam a se encontram anualmente" (BRASIL, 2019), fator este que fortaleceu a cooperação Sul-Sul entre as potências emergentes, moldando as relações internacionais em uma nova visão de integração e multilateralismo. "O cimento dos BRICS vem de um desejo compartilhado de reequilibrar as relações do poder político global e as instituições, da mesma maneira como as forças do mercado global reequilibraram o poder econômico" (KAHN, 2015, p. 194).

Em consequência, os laços diplomáticos entre Brasil e China se fortaleceram e os países assinaram um acordo comercial sobre transações financeiras (STUENKEL, 2017), no desvelar dos primeiros efeitos bilaterais gerados pela integração do BRICs. Ressalta-se que, pelo fato de a estratégia chinesa ser de ascensão pacífica e construtiva, o BRICS é visto como uma força internacional progressiva e cooperativa, não coletiva ou de competitividade, pensamento este que favorece a cooperação (NIU, 2013).

A partir do início da cooperação do BRIC, as trocas não só comerciais, como tecnológicas e diplomáticas entre o Brasil e a República Popular da China foram fortalecidas (STUENKEL, 2017). É interessante analisar a afirmação feita por Niu (2013) ao destacar, no âmbito do poder econômico, China e Brasil posicionados até 2013, respectivamente, como a segunda e a sexta maiores economias do mundo, tendo na relação bilateral sino-brasileira um forte peso à economia mundial e aos investimentos regionais, por ambos deterem status de potências regionais e incentivarem a cooperação Sul-Sul. 
A $2^{\circ}$ Cúpula Oficial dos BRICs ocorreu por iniciativa do governo Lula, na cidade de Brasília. O então presidente convidou os líderes a realizarem um diálogo de institucionalização do bloco como ente político. O bom relacionamento sino-brasileiro foi peça chave à confiabilidade do governo chinês e no aceite dos líderes chineses ao convite de participação na cúpula (STUENKEL, 2017).

A reunião em Brasília tornou-se crucial nas conexões intraBRICs, uma vez que a $2^{\circ}$ Cúpula fomentou temas abrangentes, tais como desenvolvimento agrícola, finanças e bancos centrais, intercâmbio de magistrados e juízes, e conferências de institutos de pesquisa (STUENKEL, 2017). As discussões abarcaram igualmente setores estratégicos (bancos, finanças e tecnologia), explorados posteriormente na relação bilateral Brasil-China pela evolução de uma "Parceria Estratégica Global" em 2012 (BRASIL, 2018), fundamental aos investimentos econômicos entre os Estados e ao fortalecimento dos projetos científico-tecnológicos realizados via COSBAN.

Outro evento, sediado em 2014 na cidade de Fortaleza aproximou Brasil e China: a $6^{\circ}$ Cúpula dos BRICS (BRICs mais África do Sul), tendo a concepção do Novo Banco de Desenvolvimento e do Arranjo Contingente de Reservas (ACR) como objetivos principais. Tal diálogo estreitou conexões bilaterais sino-brasileiras nos setores bancário e de financiamentos, tanto que o Brasil possui em território nacional uma sede do Banco Asiático de Investimentos em Infraestrutura (BAII), participando como membro fundador em conjunto com a China (HOLANDA, 2016).

No mesmo ano, o presidente chinês Xi Jinping marcou uma reunião com o Brasil, na qual foram celebrados 56 atos, os quais atestam a extensão das conquistas nos 40 anos de relações sinobrasileiras. Seus efeitos não só acompanharam, mas anteciparam mudanças na realidade doméstica dos dois países e em sua inserção internacional (LIMA J., 2016).

A cronologia destes acontecimentos prova que as relações entre Brasil e China majoraram gradativamente, de forma que, em 2009, quando o Brasil adentrou no bloco dos BRICs, a China tornou-se importante parceiro comercial brasileiro. E, ao sopesar 
essas conexões, identifica-se a viabilização de acordos e reuniões ministeriais envolvendo temas como o fomento intra-BRICS, saúde e educação, agricultura, bancos de desenvolvimento, transações comerciais e financeiras, incentivo de setores estratégicos como ciência, tecnologia e informação.

A consolidação dos laços construídos entre Brasil e China desde 1974 se amplificou após a incursão brasileira no BRICS, consolidando ainda mais a diplomacia entre os dois países. Entretanto, além destes encontros, acordos e reuniões, quais são as resultantes dessas relações bilaterais para ambos os países? $\mathrm{Na}$ sequência, constará uma tentativa de resposta a tal questionamento.

\section{3 - Relação bilateral Brasil-China pós-2008: acordos estratégicos e reuniões}

No ano de 2008 iniciaram as reuniões entre os líderes de Brasil, Rússia, Índia e China, coincidentes à hospitalidade entre representantes do PCCh e do presidente Lula como iniciativa de aproximação diplomática. Apesar de a relação existir antes da formação, o fato de os Estados participarem dos fóruns multilaterais dos BRICS fortaleceu diálogos no decorrer das cúpulas para a organização de reuniões bilaterais e o fomento de interesses estratégicos. No entanto, é possível afirmar que os acordos entre Brasil e China se avivaram pela participação dos Estados no bloco?

A inclusão do Brasil no BRICs, concomitante às visitas, explicita o novo direcionamento da Política Externa Brasileira, ao estabelecer diálogos bilaterais com "[...] o novo polo de poder mundial, a China" (HOLANDA, 2016, p.45). Tal destaque ao bom relacionamento sino-brasileiro faz parte do histórico diplomático entre os Estados, fortalecido pela cooperação Sul-Sul e o caráter de potência regional. Para a China, é estratégico manter laços bilaterais com o maior Estado da América do Sul, enquanto ao Brasil, torna-se importante internacionalmente se relacionar com a potência asiática ascendente.

Em 2010 e 2011, 8 reuniões diplomáticas foram realizadas sobre temas como: ligações intra-BRICS, questões de segurança 
internacional, cooperação empresarial Brasil-China, mudanças climáticas, ciência, tecnologia e inovação. Muitos diálogos ocorreram simultâneos às reuniões, comprovando o fortalecimento das trocas bilaterais sino-brasileiras, "facilitadas" pelo diálogo intra bloco. Estes encontros ocasionaram as assinaturas de dois acordos, o Plano de Ação Conjunta Brasil-China 2010-2014 e o Plano de Ação Conjunta Brasil-China em Saúde 2011-214 (BRASIL, 2018).

Sem muitas mudanças em 2012, as reuniões continuaram a ocorrer tanto no Brasil como na China, ao todo 9 encontros (BRASIL, 2018). Em prosseguimento às negociações, adveio a II Reunião da COSBAN e, apesar de seu caráter bilateral, os assuntos abordados foram de cunho multilateral: representantes brasileiros e chineses assinalaram a importância da integração regional para o desenvolvimento da cooperação multilateral entre os Estados, e classificaram como ineficaz o modelo organizacional das Nações Unidas no enfrentamento dos "desafios globais atuais" (MOREIRA, 2016). As conversas mantidas na Segunda Plenária resultaram na “[...] elevação das relações ao nível de Parceria Estratégica Global e criação do Diálogo Estratégico Global entre Chanceleres" (BRASIL, 2018, não paginado).

Naquele momento, a junção Brasil-China foi promovida à parceria estratégica e, dois anos mais tarde, ocorreu a $1^{\circ}$ Reunião do Diálogo Estratégico Global. O restante do período marca a assinatura da Declaração Conjunta Brasil-China, inúmeras visitas de representantes e o lançamento do satélite CBERS 4, em sequência às cooperações tecnológicas sino-brasileiras (BRASIL, 2018).

O ano de 2013 foi marcado por uma reunião bilateral realizada "[...] à margem da Cúpula dos BRICS, em Durban, África do Sul" (BRASIL, 2018, não paginado), reforçando a ideia dos BRICS como facilitador para as conexões diplomáticas entre Brasil e China. Além deste encontro entre os presidentes dos países, somaram-se mais 8 reuniões, em sua maioria de cunho bilateral, com o destaque para temas migratórios, consulares, e o lançamento do CBERS (BRASIL, 2018), fruto das cooperações em tecnologias e dos investimentos financeiros no setor realizadas via COSBAN. 
$|14|$

O papel dos Brics nas relações diplomáticas...

Em 2015 mantiveram-se os encontros costumeiros, alguns envolvendo debates multilaterais, tais como a reunião dos Ministros das Relações Exteriores do BRICS, com ênfase à continuidade da cooperação sino-brasileira no setor tecnológico, por meio da IV Sessão Plenária da COSBAN e do II Diálogo de Alto Nível Brasil-China em Ciência, Tecnologia e Inovação (BRASIL, 2018). Na sequência, o Brasil passou por transformações causadas pelo impeachment da então Presidenta Dilma Rousseff, e a ascensão à presidência de Michel Temer.

Mesmo com poucas implicações ao longo do mandato, notase o foco do governo Temer na China, a primeira nação visitada após a posse presidencial. Na ocasião, Michel Temer participou do Seminário Empresarial de Alto Nível Brasil-China (Xangai) e da XI Cúpula do G20 (Hangzhou). No ano de 2017, o Ministro das Relações Exteriores do Brasil integrou reuniões estratégicas, como o Diálogo Estratégico Global Brasil-China e o Encontro com os Chanceleres do BRICS, em Pequim (BRASIL, 2019).

Em setembro do mesmo ano, o presidente Michel Temer tomou parte da IX Cúpula dos BRICS, na cidade de Xiamen, China, cujos diálogos foram estendidos a países convidados, como Egito, Guiné, México, Tajiquistão e Tailândia. O discurso do presidente brasileiro na plenária da IX Cúpula dos BRICS referiu-se à necessidade brasileira de "[...] consolidação da parceria econômica (sobretudo por meio do Novo Banco de Desenvolvimento e do Arranjo de Contingente de Reservas) [...]" (TEMER, 2018). Acrescenta-se ainda que, das viagens efetuadas por Temer, 19\% foram para países do bloco, um aumento significativo se comparado ao governo Dilma, que totalizou apenas 7\% (SILVA, 2019).

Assim, enquanto a ênfase dos presidentes anteriores era dada à política do bloco, Temer visualizava no BRICS uma saída mais direta da crise pela continuidade das relações multilaterais, porém, com relativa mudança quanto à evidência do bloco, deslocada para a instância econômica (SILVA, 2019).

Dados do Ministério das Relações Exteriores (BRASIL, 2018) demonstram que as iniciativas bilaterais sino-brasileiras tratadas por acordos e reuniões aumentaram nas fases do governo Lula, 
existindo continuidade moderada no governo Dilma, que decaiu para um histórico de reuniões formais e assinatura de poucos acordos no governo Michel Temer.

Diante dos fatos expostos, observa-se o papel crucial da relação intra-BRICS como facilitador na aproximação diplomática entre Brasil e China, cujo diálogo ofereceu um cenário favorável ao desenvolvimento de relações bilaterais. Por meio das reuniões do bloco, os líderes estatais identificaram interesses em comum e passaram, no conluio intra-BRICS, a atuar em favor dos setores de interesse comum, tais como o tecnológico, o mais desenvolvido nesta relação.

Garay Vargas (2018) alerta que os cinco países membros do BRICS (o que inclui China e Brasil) reivindicam tratamento diferenciado na esfera internacional porque ainda não são considerados "desenvolvidos", vendo a si mesmos como objeto das políticas de redistribuição. Também sofrem com instabilidades, em grande medida econômicas e políticas que, somadas às diferenças e particularidades de cada um, podem dificultar a cooperação almejada. Em contrapartida, a China ocupa posição dominante no mercado de manufaturados e na diversificação da pauta exportadora, sendo beneficiada pela oferta de commodities.

Não obstante, é impossível negar a interferência das mudanças governamentais na relação sino-brasileira, tendo no governo Lula o precursor da entrada do Brasil no BRICS. Com uma diplomacia direcionada aos interesses do bloco, essas relações cresceram, mas decaíram em consequência das mudanças governamentais no Brasil. Todavia, mesmo com a diminuição dos acordos, observa-se o interesse chinês nas parcerias com o Brasil, não somente dentro do BRICS, mas com um forte laço bilateral, o que a coloca entre os principais parceiros econômicos brasileiros na atualidade.

Este é um sinal de alerta: a China, a partir de um discurso que prega a cooperação, firma acordos que, em um primeiro momento, elevam a prosperidade de países como o Brasil em curto prazo, minimizando a percepção de dependência econômica. Mas a baixa demanda por commodities apresentada pela China nos últimos 
$|16|$

O papel dos Brics nas relações diplomáticas...

anos agravou a crise econômica que o Brasil enfrenta hoje, o que exemplifica uma relação também de dependência.

Porém, os elementos relacionados demonstram ser inegável a importância da China como parceiro comercial e a posição do BRICS na construção de canais de cooperação entre seus países formadores, situação esta que poderá auxiliar o Brasil a retomar os rumos do crescimento.

\section{Referências}

BARBIERI JUNIOR, W. Uma análise do processo de constituição do Estado nacional como eixo de ascensão chinesa no capitalismo internacional. 2015. $214 \mathrm{f}$. Tese (Doutorado) - Universidade de São Paulo, 2015. Disponível em: <https://tede2.pucsp.br/handle/ handle/3681> Acesso em 16 fev. 2018.

BECARD, D. S. R. O que esperar das relações BrasilChina? Revista de Sociologia e Política. Curitiba, v. 19, n. 1, p.3144, nov. 2011. Disponível em: <http://dx.doi.org/10.1590/S010444782011000400004>. Acesso em: 10 jun. 2018.

BECARD, D. S. R. O Brasil e a República Popular da China: Política Externa Comparada e Relações Bilaterais (1974-2004). Brasília: FUNAG, 2008. Disponível em: < http:/funag.gov.br/loja/ index.php?route=product/product\&product_id=468>. Acesso em: 07 jun. 2018.

BIATO, O. A Parceria Estratégica Sino-Brasileira: Origens, Evolução e Perspectivas (1993-2006). Brasília: FUNAG, 2010. Disponível em: <http://funag.gov.br/biblioteca/download/899-A_ Parceria_Estrategica_Sino-Brasileira.pdf $>$. Acesso em: 13 mai. 2019.

BRASIL. Ministério das Relações Exteriores. República Popular da China. Disponível em: <http://www.itamaraty.gov.br/pt-BR/ ficha-pais/4926-republica-popular-da-china>. Acesso em: 16 junho 2018. 
BRASIL. Ministério das Relações Exteriores. BRICS - Brasil, Rússia, Índia, China e África do Sul. Disponível em: <http:// www.itamaraty.gov.br/pt-BR/politica-externa/mecanismos-interregionais/3672-brics>. Acesso em: 30 jun. 2019.

BRENER, J. Trinta anos de não-alinhados. Lua Nova, v. 3, n. 3, São Paulo, 1987. Disponível em: < http://www.scielo.br/scielo. php?script=sci_arttext\&pid=S0102-64451987000100016>. Acesso em: 20 abr. 2018.

DICK, P. P. A parceria estratégica entre Brasil e China: a contribuição da política externa brasileira (1995-2005). 2006, 214 f. Dissertação (Mestrado) - Universidade Federal do Rio Grande do Sul, Porto Alegre, 2006. Disponível em: <http://www.lume. ufrgs.br/bitstream/handle/10183/8089/000567388.pdf?sequence=1> Acesso em: 16 jun. 2018.

GARAY VARGAS, J. L. Cuestionando consensos: algunos apuntes frente al - ¿eventual? - ascenso de los BRICS como poderes globales. Desafíos, [s.1.], v. 30, n. 2, p. 237-278, jun. 2018. Disponível em: < https://revistas.urosario.edu.co/index.php/desafios/article/ view/5578/5684>. Acesso em: 11 mai. 2019.

GONÇALVES, W. da S.; MIYAMOTO, S. Os Militares Na Política Externa Brasileira: 1964-1984. Estudos Históricos, Rio de Janeiro, v. 6, n. 12, p. 211-246, 1993.

HOSBAWM, E. Era dos Extremos: o breve século XX (1914-1991). São Paulo: Companhia das Letras, 1994.

HOLANDA, F. M. B. 40 anos das Relações Brasil-China: de onde viemos, onde estamos, para onde vamos. In: LIMA, S. E. M. Brasil e China: 40 anos de relações diplomáticas. Brasília: FUNAG, 2016, p.35-56.

KAHN, M. A cooperação dos BRICS na ciência, tecnologia e inovação: retórica e realidades. Contexto Internacional, Rio de Janeiro, v. 37, n. 1, p. 185-213, abr. 2015. Disponível em: $<$ http://www.scielo.br/scielo.php?script=sci_arttext\&pid=S010285292015000100185\&lng=pt\&nrm=iso>. Acesso em: 27 jun. 2018. 
$|18|$

O papel dos Brics nas relações diplomáticas...

LIMA, J. A. G. Perspectivas das Relações Sino-Brasileiras após a visita do presidente Xi Jinping. In: LIMA, S. E. M. Brasil e China: 40 anos de relações diplomáticas. Brasília: FUNAG, 2016, p.21-34.

LIMA, M. R. S. de. A política externa brasileira e os desafios da cooperação Sul-Sul. Revista Brasileira de Política Internacional, Brasília, v. 48, n. 1, p. 24-59, jan./jun. 2005, pp.24-59. Instituto Brasileiro de Relações Internacionais. Disponível em: < http:// www.scielo.br/pdf/rbpi/v48n1/v48n1a02.pdf $>$. Acesso em: 7 jun. 2018.

LIMA, S. E. M. Prefácio. In: __ Brasil e China: 40 anos de relações diplomáticas. Brasília: FUNAG, 2016a, p.13-20.

LIMA, S. E. M. Anexo A: Ata Final da Segunda Sessão Plenária da Comissão Sino-Brasileira de Alto Nível de Concertação e Cooperação (COSBAN). In: __ Brasil e China: 40 anos de relações diplomáticas. Brasília: FUNAG, 2016b, p.185-214.

NIU, H. A grande estratégia Chinesa e os BRICS. Contexto Internacional. Rio de Janeiro, v. 35, n. 1, p. 197-229, jun. 2013. Disponível em: <http://www.scielo.br/scielo.php?script=sci_ arttext\&pid=S0102-85292013000100007\&lng=pt\&nrm=iso $>$. Acesso em: 27 jun. 2018.

OLIVEIRA, H. A. de. Brasil-China: trinta anos de uma parceria estratégica. Revista Brasileira de Política Internacional, [s.l.], v. 47, n. 1, p. 7-30, 2004. Disponível em: <http://www.scielo.br/scielo. php?script=sci_arttext\&pid=S0034-73292004000100002\#nt24> Acesso em: 16 junho 2018.

RICUPERO, R. A diplomacia na construção do Brasil (1750-2016). Rio de Janeiro: Versal Editores, 2017.

SARAIVA, M. G. As estratégias de cooperação Sul-Sul nos marcos da política externa brasileira de 1993 a 2007. Revista de Política Internacional, v. 2, n. 50, p. 42-59, 2007. Disponível em: <http:// www.scielo.br/pdf/rbpi/v50n2/a04v50n2.pdf>. Acesso em: 11 jun. 2018. 
SENADO FEDERAL. República Popular da China. Disponível em: <https://legis.senado.leg.br/sdleg-getter/ documento? $\mathrm{dm}=7733829 \&$ disposition=inline $>$ Acesso em: 19 junho 2018.

SILVA, A. V. C. A política externa do governo Michel Temer (2016-2018): mudanças para a legitimidade? Um teste da teoria de Charles Hermann. Conjuntura Austral, Porto Alegre, v. 10, p. 2341, 2019. Disponível em: <https://seer.ufrgs.br/ConjunturaAustral/ article/view/86954>. Acesso em: 17 maio 2019.

STUENKEL, O. BRICS e o futuro da ordem global. Rio de Janeiro; São Paulo: Paz e Terra, 2017.

TEMER, Michel. O Brasil no Mundo: Abertura e Responsabilidade. Brasília: Fundação Alexandre de Gusmão, 2018.

VALENTE, Leonardo; ALBUQUERQUE, Marianna. Da Discrição ao Ativismo: O Novo Papel da China no Conselho de Segurança da ONU. Revista Contexto Internacional. São Paulo, v.37, n. 2. p. 693-726, mai. 2015.

VÉRAS, D. B. República Federativa do Brasil e República Popular da China: 41 anos de relações diplomáticas. 27 nov. 2015. Disponível em: <http://politica-china.org/areas/politica-exterior/ republica-federativa-do-brasil-e-republica-popular-da-china-41anos-de-relacoes-diplomaticas>. Acesso em: 18 jun. 2018.

VIGEGANI, T.; OLIVEIRA, M.; CINTRA, R. Política externa no período FHC: a busca de autonomia pela integração. Tempo Social, v. 15, n. 2, p. 31-61, 2003. Disponível em: <http://www.scielo.br/ scielo.php? script=sci_arttext\&pid=S0103-20702003000200003>. Acesso em: 14 mai. 2019.

VIZENTINI, P. F. De FHC a Lula: uma década de política externa (1995-2005). Civitas, v. 5, n. 2, p.381-397, 2005. Disponível: <http:// revistaseletronicas.pucrs.br/ojs/index.php/civitas/article/view/9>. Acesso em: 17 mai. 2019. 